\title{
Adaptation to Increased Dietary Salt Intake in the Rat Role of Endogenous Nitric Oxide
}

\author{
Pamela J. Shultz and Jonathan P. Tolins \\ Department of Medicine, Veterans Affairs Medical Center and University of Minnesota School of Medicine, \\ Minneapolis, Minnesota 55417
}

\begin{abstract}
Previous studies have suggested that nitric oxide (NO) plays a role in regulation of renal vascular tone and sodium handling. We questioned whether the effects of NO synthase inhibition on renal function are direct or due to increased renal perfusion pressure (RPP) and whether stimulation of endogenous NO activity plays a role in adaptation to increased dietary salt intake. Intrarenal arterial infusion of the NO synthase inhibitor $\mathbf{N}^{\mathbf{G}}$-monomethyl-L-arginine (L-NMMA) in control rats resulted in decreased glomerular filtration rate, renal vasoconstriction, natriuresis, and proteinuria. When RPP was held at basal levels with a suprarenal aortic snare, L-NMMA had similar hemodynamic effects but decreased sodium excretion and did not induce proteinuria. Exposure of rats to high salt intake ( $1 \% \mathrm{NaCl}$ drinking water) for 2 wk induced increased serum concentration and urinary excretion of the $\mathrm{NO}$ decomposition products, $\mathrm{NO}_{2}+\mathrm{NO}_{3}$. Urinary $\mathrm{NO}_{2}+\mathrm{NO}_{3}$ and sodium excretion were significantly correlated. Compared with controls, chronically salt-loaded rats also demonstrated enhanced renal hemodynamic responses to NO synthase inhibition. We conclude that the endogenous NO system directly modulates renal hemodynamics and sodium handling and participates in the renal adaptation to increased dietary salt intake. Enhanced NO synthesis in response to increased salt intake may facilitate sodium excretion and allow maintenance of normal blood pressure. (J. Clin. Invest. 1993. 91:642-650.) Key words: endothelium-derived relaxing factor $\bullet$ nitric oxide $\bullet \mathbf{N}^{\mathbf{G}}$-monomethyl-Larginine $\bullet$ nitro-L-arginine-methylester $\bullet$ sodium $\bullet$ natriuresis
\end{abstract}

\section{Introduction}

In 1980, Furchgott and Zawadski ( 1 ) demonstrated that vascular relaxation induced by the muscarinic agent acetylcholine was dependent on the presence of a functionally intact endothelium and postulated the release by endothelial cells of a labile

Parts of this work were presented at the Annual Meetings of the American Federation for Clinical Research, Baltimore, MD, 1-4 May 1992, and have been published in abstract form (1992. Clin. Res. 40:353A).

Address reprint requests to J. P. Tolins, M. D., Veterans Administration Medical Center Renal Section 111-J, 1 Veterans Drive, Minneapolis, MN 55417.

Received for publication 21 May 1992 and in revised form 3 September 1992.

The Journal of Clinical Investigation, Inc.

Volume 91, February 1993, 642-650 factor termed endothelium-derived relaxing factor (EDRF). ${ }^{1}$ Since that initial observation our understanding of the EDRF system has expanded rapidly. It is currently believed that EDRF is nitric oxide (NO), which is derived from the terminal guanidino nitrogen atom of the aminoacid, L-arginine (2-6). A soluble enzyme, currently termed NO synthase, is involved in the formation of $\mathrm{NO}$ and $\mathrm{L}$-citrulline from L-arginine $(7,8)$. Synthesis of NO can be inhibited by L-arginine analogues such as $\mathrm{L}-N^{\mathrm{G}}$-monomethyl-arginine (L-NMMA) and $\mathrm{L}-N^{\mathrm{G}}$-nitroarginine-methylester (L-NAME) (9-11). In vitro studies have demonstrated that NO activates soluble guanylate cyclase in target cells, such as vascular smooth muscle (12) and glomerular mesangial cells (13), inducing a rise in levels of guanosine 3',5'-cyclic monophosphate (cGMP), which mediates subsequent physiological effects. Urinary cGMP levels have also been demonstrated to reflect activity of the NO system in vivo (14).

Using this understanding of the basic physiology of the endogenous NO system, attention has recently focused on the role of this mediator in the regulation of vascular tone in vivo. By observing the effects in vivo of endothelium-dependent agonists, such as acetylcholine, and NO synthase inhibitors, such as L-NMMA and L-NAME, it has become clear that NO plays a prominent role in regulation of renal hemodynamics and excretory function (15-20). When infused into the renal artery of the rat, L-NMMA induces a fall in GFR and renal vasoconstriction and a rise in filtration fraction (15). Micropuncture studies in the rat during intravenous infusion of L-NMMA have demonstrated glomerular arteriolar vasoconstriction, with a predominant effect on the efferent arteriole, a decrease in the ultrafiltration coefficient, $K_{\mathrm{f}}$, and an increase in glomerular capillary pressure, $\mathrm{Pgc}$ (16).

Several investigators have reported that NO synthase inhibition in vivo induces natriuresis and diuresis $(16,17,20)$. Although some investigators have suggested that the increased excretion of sodium and water during NO inhibition is due to "pressure natriuresis" $(18,21)$, others have hypothesized a direct tubular action of NO, observing that NO synthase inhibition results in decreased proximal reabsorption of sodium (20). This issue has been complicated by the difficulty in separating direct renal effects of NO synthesis inhibition from systemic hemodynamic effects, such as increased arterial pressure

1. Abbreviations used in this paper: cGMP, guanosine 3',5'-cyclic monophosphate; EDRF, endothelium-derived relaxing factor; LNAME, nitro-L-arginine-methylester; L-NMMA, $N^{\mathrm{G}}$-monomethyl-Larginine; $\mathrm{NO}$, nitric oxide; $\mathrm{NO}_{2}$, nitrite; $\mathrm{NO}_{3}$, nitrate; $\mathrm{PAH}$, paraaminohippurate; RPF, renal plasma flow; RPP, renal perfusion pressure; RVR, renal vascular resistance. 
and subsequent renal autoregulation, in the various experimental models. Chen and Sanders ( 22 ) recently suggested that activity of the endogenous NO system may be related to sensitivity or resistance to salt-induced hypertension in rats, further suggesting a role for NO in renal sodium handling, and, in particular, in adaptation to increased dietary salt loads.

Since NO is a very labile substance, direct measurement of NO has proven to be difficult, especially in vivo. Thus, much of the in vivo work to date has been limited to interpretation of the responses to NO synthase inhibitors. Although this is a useful approach, it is clear that it would be important to develop markers of NO activity that could be quantitated in vivo. Tolins et al. (14), previously demonstrated that, in the rat, hemodynamic responses to the endothelium-dependent vasoactive agonist, acetylcholine, correlated with urinary excretion of cGMP, and that the cGMP and hemodynamic responses to acetylcholine infusion could be inhibited by administration of L-NMMA. These investigators suggested that urinary cGMP excretion could potentially be used as a biological marker of EDRF activity. More recently, Marletta et al. (23) demonstrated that NO decomposes rapidly in biological solutions into nitrite $\left(\mathrm{NO}_{2}\right)$ and nitrate $\left(\mathrm{NO}_{3}\right)$. These stable decomposition products can be measured as markers of NO production in vitro, as demonstrated in macrophages (23), vascular smooth muscle (24), and glomerular mesangial cells (25) in culture. Recently, $\mathrm{NO}_{2}+\mathrm{NO}_{3}$ have been used as markers of NO activity in vivo. Shultz and Raij (26) reported increases in levels of $\mathrm{NO}_{2}+\mathrm{NO}_{3}$ in the serum and urine of rats treated with endotoxin. The increase in $\mathrm{NO}_{2}+\mathrm{NO}_{3}$ levels was inhibited by coadministration of the NO synthase inhibitor, L-NAME. Furthermore, this inhibitory effect was overcome by administration of excess L-arginine, confirming that the $\mathrm{NO}_{2}+\mathrm{NO}_{3}$ measured in the serum and urine after endotoxin reflected changes in NO production. Thus, urinary levels of cGMP, as well as serum and urine levels of $\mathrm{NO}_{2}+\mathrm{NO}_{3}$, may be useful as in vivo "footprints" of activity of the NO pathway.

In the present studies we have used both the pharmacological inhibitors of NO synthase and markers of in vivo NO production to address the following questions: What is the effect of inhibition of NO synthase on renal hemodynamics and excretory function when the influence of systemic hemodynamic responses is eliminated? Does the endogenous NO system play a role in adaptation of the normal animal to increased dietary salt intake?

\section{Methods}

Studies were performed in male, Sprague-Dawley rats (275-375 g; Harlan Sprague Dawley, Inc., Indianapolis, IN). In study I we examined the effects of intrarenal NO synthase inhibition on renal hemodynamics and excretory function when renal perfusion pressure was kept constant with a suprarenal aortic snare. In study II we examined the effects of chronic exposure to a high dietary salt intake on endogenous NO activity.

Study I. Role of increased renal perfusion pressure in the effects of NO synthase inhibition on renal hemodynamics and excretory function

Clearance studies. Rats were anesthetized (Inactin, $100 \mathrm{mg} / \mathrm{kg}$ i.p.) and surgically prepared for determination of intra-arterial pressure, GFR, renal plasma flow (RPF), and urinary excretion of sodium, water and protein, by clearance techniques as previously described ( 14 ,
15). The left femoral artery was cannulated with a PE-50 catheter for blood pressure monitoring (transducer model TNf; Gould Inc., Medical Products Div., Oxnard, CA) and blood sampling. Renal perfusion pressure (RPP) was assumed to be equivalent to the arterial pressure measured in the left femoral artery. A solution of normal saline containing [methoxy- ${ }^{3} \mathrm{H}$ ]inulin $(4 \mu \mathrm{Ci} / \mathrm{ml})$ and $p$-aminohippurate (PAH, $20 \mathrm{mg} / \mathrm{ml}$; Merck Sharpe \& Dohme, West Point, PA) was infused at a rate of $1.2 \mathrm{ml} / \mathrm{h}$ after a priming dose of $0.5 \mathrm{ml}$. To maintain euvolemia, $5 \%$ bovine serum albumin in normal saline (Sigma Chemical Co., St. Louis, MO) was infused at $1.5 \mathrm{ml} / \mathrm{h}$ after a priming dose of $1 \%$ body weight. Timed urine collections were obtained from the left ureter for gravimetric determination of urine flow rate, with blood collected at the midpoint of each clearance period $(250 \mu \mathrm{l})$.

For renal artery infusions, a PE-10 catheter with a curved attenuated tip was advanced in a retrograde fashion from the right femoral artery and placed in the orifice of the left renal artery under direct visualization. In this fashion, dissection and manipulation of the renal artery were unnecessary and thus potential denervation or vascular damage avoided. To maintain patency in the renal artery catheter, heparinized saline was infused at a rate of $0.5 \mathrm{ml} / \mathrm{h}$ when other agents were not being administered.

Analytical techniques. Radioactivity in urine and serum was quantitated by liquid-scintillation counting. PAH levels in urine and serum were determined by AutoAnalyser (Technicon Instruments Corp., Tarrytown, NY). Urine sodium was determined by flame photometer (Instrumentation Laboratory Inc., Lexington, MA). Urinary total protein excretion was assayed by the Coomassie dye method (Bio-Rad Laboratories, Richmond, CA). GFR and RPF were calculated with standard formulas. Renal blood flow (RBF) was calculated by dividing RPF by 1 - hematocrit and renal vascular resistance was calculated (RVR) by dividing RPP by renal blood flow.

Experimental protocols. Two groups of rats ( $n=8$ in each group) were studied after overnight fast. Group I rats (control) were allowed to equilibrate for $30 \mathrm{~min}$ after surgical preparation and then two baseline ( $15 \mathrm{~min}$ ) clearances were performed. The intrarenal infusion was then changed to L-NMMA (generous gift of S. Moncada, Wellcome Research Laboratories, Beckenham, Kent, UK) dissolved in normal saline and delivered at 250 and $500 \mu \mathrm{g} \cdot \mathrm{kg}^{-1}$ per min. There was a 15 -min equilibration period at each dose level followed by two 15 -min clearance periods. In group II (snare) rats, a length of suture was placed around the abdominal aorta, proximal to the renal arteries, during surgical preparation. The ends of the suture were suspended in an apparatus that allowed graded upward tension to be applied. Group II rats then underwent a protocol identical to that in group I with the exception that after the baseline clearances, the tension on the aortic snare was continuously adjusted to maintain RPP at baseline levels. An additional group of rats $(n=6)$ was prepared for clearance studies in a manner identical to that of group II ( snare) except that no tension was applied to the aortic snare. Saline vehicle was infused into the renal artery $(0.5 \mathrm{ml} / \mathrm{h})$ for the duration of the experiment. Renal function was determined according to the exact protocol described above, thus providing a time-control group.

\section{Study II. Experimental protocols}

Effect of salt loading on serum $\mathrm{NO}_{2}+\mathrm{NO}_{3}$ levels and urinary $\mathrm{NO}_{2}$ $+\mathrm{NO}_{3}$ excretion rates. Two groups of rats ( $n=6$ in each group) were studied. On day 0 , while consuming standard rat chow and tap water ab libitum, all rats were placed in metabolic cages and urine was collected for $24 \mathrm{~h}$ in sterile tubes containing antibiotic/antimycotic solution $(100 \mathrm{U} / \mathrm{ml}$ penicillin, $100 \mathrm{U} / \mathrm{ml}$ streptomycin, and $0.25 \mu \mathrm{g} / \mathrm{ml} \mathrm{am-}$ photericin B). Blood was obtained by distal tail-vein sampling for determination of serum $\mathrm{NO}_{2}+\mathrm{NO}_{3}$. Group III (control) was continued on standard rat chow and tap water ad libitum. Group IV (salt loaded) was provided the same chow, but was switched to $1 \% \mathrm{NaCl}$ solution as drinking water. After 2 wk rats were placed in metabolic cages, urine collected for $24 \mathrm{~h}$, and final blood samples obtained by cardiac puncture after brevital anesthesia. 
Serum and urine samples were assayed for the stable NO end products, $\mathrm{NO}_{2}$ and $\mathrm{NO}_{3}$, as previously described (26-28). Briefly, samples were incubated for $1 \mathrm{~h}$ at $37^{\circ} \mathrm{C}$ with Escherichia coli nitrate reductase, prepared from bacteria grown under anaerobic conditions, effecting complete reduction of $\mathrm{NO}_{3}$ in the sample to $\mathrm{NO}_{2} . \mathrm{NO}_{2}$ in the sample was then quantitated using the Griess reagent, as previously described $(25,26,29)$. Known concentrations of $\mathrm{NaNO}_{2}$ and $\mathrm{NaNO}_{3}$ were used as standards in each assay and each sample was run in duplicate. The $\mathrm{NO}_{2}$ measured in this way reflects the sum of $\mathrm{NO}_{2}$ and $\mathrm{NO}_{3}$ in the original sample. Urinary excretion was calculated by multiplying the total concentration of $\mathrm{NO}_{2}+\mathrm{NO}_{3}$ in each sample by 24-h urinary volume. Because rats exhibited significant increases in body weight over the course of the experiment, $\mathrm{NO}_{2}+\mathrm{NO}_{3}$ values were normalized for body weight to allow comparison of basal and final values. Baseline and final urine samples were also assayed for cGMP concentration by radioimmunoassay as previously described $(14,25)$ and for sodium concentration by flame photometer.

Effect of chronic salt loading on renal hemodynamic responses to NO synthase inhibition. Two additional groups of rats $(n=10$ in each group) were studied. Group V (control) was provided standard rat chow and tap water, whereas group VI (salt loaded) received standard rat chow and $1 \% \mathrm{NaCl}$ in the drinking water, for $2 \mathrm{wk}$. At the end of this time period rats in groups $\mathrm{V}$ and VI were surgically prepared for clearance studies to evaluate renal function before and after intrarenal infusion of the NO synthase inhibitor, L-NAME, infused at 50 and 125 $\mu \mathrm{g} \cdot \mathrm{kg}^{-1}$ per min using a protocol identical to that described above for group I rats. Pilot studies demonstrated that renal artery infusion of the higher dose of L-NAME (125 $\mu \mathrm{g} \cdot \mathrm{kg}^{-1}$ per min) results in maximal renal hemodynamic responses (unpublished observations).

\section{Statistical analysis}

Data are presented as mean \pm SEM. Differences for parameters between baseline and subsequent time points within one group were compared by analysis of variance for repeated measures and subsequent Scheffe test. Differences between two groups at a given time point were compared by unpaired Student's $t$ test. Differences were considered significant for $P<0.05$. All statistical analyses were done with STATVIEW 512 software (Brainpower, Calabases, CA).

\section{Results}

Study I. Role of renal perfusion pressure in response of renal hemodynamics and excretory function to NO synthase inhibition

There was no difference in body weight ( $384 \pm 7$ vs. $390 \pm 6 \mathrm{~g}, P$ $=\mathrm{NS})$ or left kidney weight $(1.39 \pm 0.04$ vs. $1.41 \pm 0.03 \mathrm{~g}, P$
= NS) between group I (control) and group II (aortic snare) rats. Renal hemodynamic parameters in the basal state and in response to intrarenal arterial infusion of L-NMMA at 250 and $500 \mu \mathrm{g} \cdot \mathrm{kg}^{-1}$ per min are shown in Table I. In control rats intrarenal arterial infusion of L-NMMA induced a dose-dependent increase in RPP, reflecting a systemic pressor response occuring despite intrarenal infusion. Both GFR and RPF progressively and significantly decreased during L-NMMA infusion, in association with marked renal vasoconstriction. In group II (aortic snare) rats initial RPP was slightly, but significantly elevated compared with control animals; however, RPP was effectively maintained at basal levels during L-NMMA infusion. There was no difference in GFR, RPF, or RVR between group I and group II rats in the basal state, indicating that placing the aortic snare did not effect basal renal function. In snared rats GFR and RPF decreased in a dose-dependent fashion in response to intrarenal L-NMMA infusion, falling to significantly lower levels as compared with group I at the highest dose. L-NMMA infusion also resulted in renal vasoconstriction, as reflected in a progressive increase in RVR. The magnitude of the increase in RVR was similar in group I and group II rats. Thus, intrarenal EDRF inhibition resulted in exaggerated decreases in GFR and RPF when the concomitant increase in RPP was prevented.

In time control rats an aortic snare was placed, but no tension was applied, and saline vehicle was infused into the renal artery. Renal hemodynamics were determined at time points corresponding to measurements in groups I and II. This group of rats had body weights $(379 \pm 10 \mathrm{~g})$ and left kidney weights $(1.34 \pm 0.04 \mathrm{~g})$ that were similar to those of rats in groups I and II. Hematocrit was stable over the time course of the experiment (basal vs. final, $51.2 \pm 0.9$ vs. $50.5 \pm 1.0 \%, P=\mathrm{NS}$ ). RPP did not change over the course of the experiment in time control rats (basal vs. final, $121 \pm 4$ vs. $118 \pm 2 \mathrm{mmHg}, P=\mathrm{NS}$ ). GFR had decreased somewhat by the end of the protocol (basal vs. final, $0.98 \pm 0.06$ vs. $0.76 \pm 0.03 \mathrm{ml} / \mathrm{min}, P<0.05$ ), however, RPF (basal vs. final, $5.01 \pm 0.29$ vs. $5.44 \pm 0.36 \mathrm{ml} / \mathrm{min}, P$ $=\mathrm{NS}$ ) and RVR (basal vs. final, $12.09 \pm 0.82$ vs. $11.05 \pm 0.71$ $\mathrm{mmHg} \cdot \min ^{-1}$ per $\mathrm{ml}, P=\mathrm{NS}$ ) were unchanged over the course of the experiment.

The effect of intrarenal infusion of L-NMMA on urinary excretion of sodium, water, and protein in rats of groups I and

Table I. Renal Hemodynamic Parameters of Rats in Study I

\begin{tabular}{|c|c|c|c|c|}
\hline Group & RPP & GFR & RPF & RVR \\
\hline & $m m H g$ & & & $m m H g \cdot \min ^{-1}$ per $m l$ \\
\hline \multicolumn{5}{|l|}{ Group I } \\
\hline Control, baseline & $116 \pm 3$ & $0.97 \pm .04$ & $5.47 \pm .36$ & $11.04 \pm .65$ \\
\hline \multicolumn{5}{|l|}{ L-NMMA } \\
\hline $250 \mu \mathrm{g} \cdot \mathrm{kg}^{-1}$ per min & $129 \pm 3^{*}$ & $0.86 \pm .02^{*}$ & $4.69 \pm .18^{*}$ & $14.09 \pm .59^{*}$ \\
\hline $500 \mu \mathrm{g} / \mathrm{kg} / \mathrm{min}$ & $138 \pm 2^{*}$ & $0.69 \pm .02^{*}$ & $3.88 \pm .28^{*}$ & $18.83 \pm 1.06^{*}$ \\
\hline \multicolumn{5}{|l|}{ Group II } \\
\hline Snare, baseline & $126 \pm 2^{\dagger}$ & $0.99 \pm .06$ & $5.52 \pm .31$ & $11.39 \pm .56$ \\
\hline \multicolumn{5}{|l|}{ L-NMMA } \\
\hline $250 \mu \mathrm{g} / \mathrm{kg} / \mathrm{min}$ & $126 \pm 2$ & $0.85 \pm .02^{*}$ & $4.64 \pm .24^{*}$ & $13.60 \pm .71$ \\
\hline $500 \mu \mathrm{g} / \mathrm{kg} / \mathrm{min}$ & $126 \pm 2^{\dagger}$ & $0.61 \pm .03^{* \dagger}$ & $3.21 \pm .24^{* \dagger}$ & $20.69 \pm 1.98^{*}$ \\
\hline
\end{tabular}

Refer to glossary for definition of terms. All values expressed as mean \pm SEM. ${ }^{*} P<0.05$ vs. baseline; ${ }^{\dagger} P<0.05$ group II vs. group I same period. 

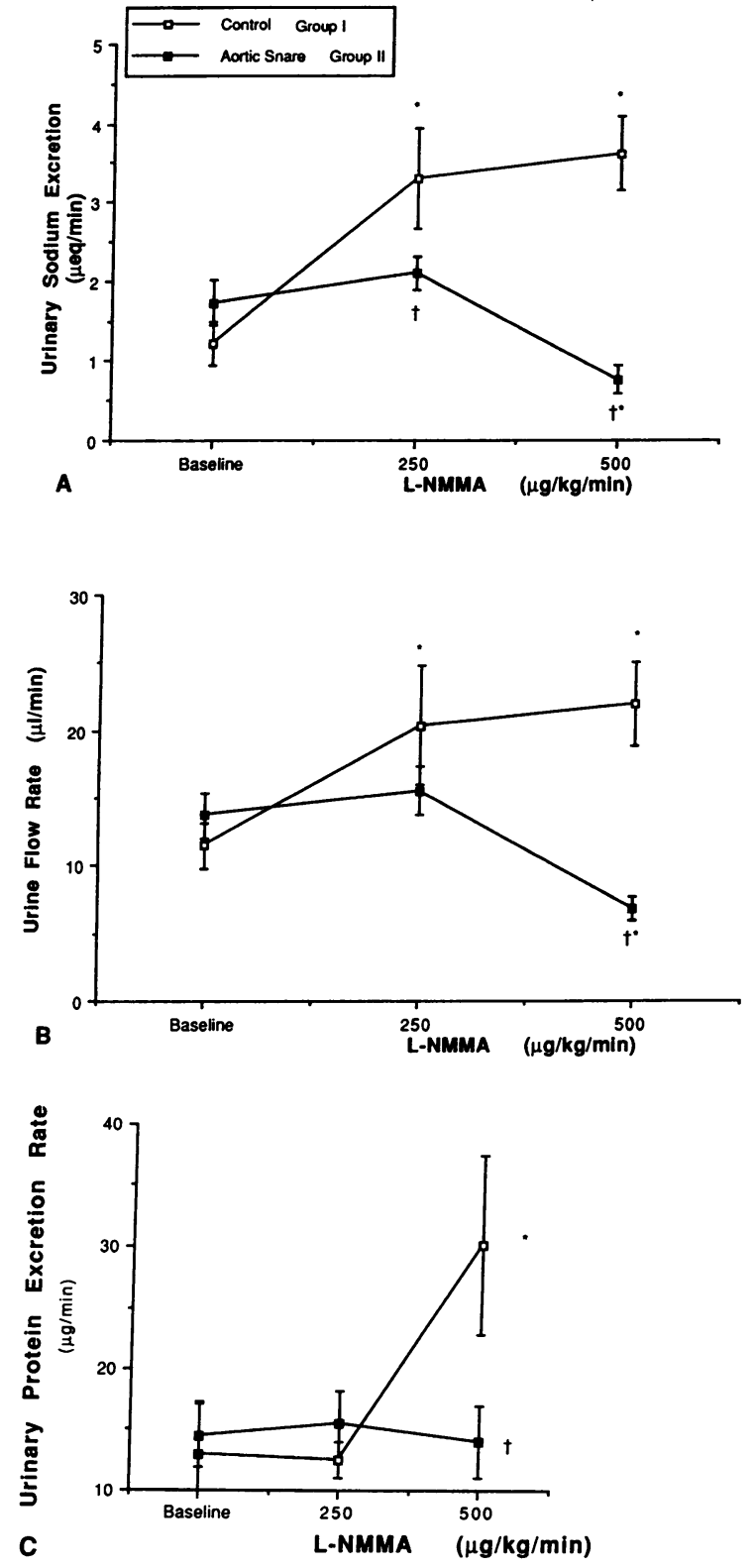

Figure 1. Renal excretory function in rats of study I in the baseline and after renal arterial infusion of the NO synthase inhibitor, $\mathrm{L}$ NMMA. Urinary excretion rates of sodium $(A)$, water $(B)$, and protein $(C)$ are shown for control rats (group I), in whom RPP varied spontaneously, and aortic-snare rats (group II), in whom RPP was fixed at baseline levels. ${ }^{*} P<0.05$ vs. baseline; $\uparrow P<0.05$ group I vs. group II.

II is shown in Fig. 1. In control rats, in whom RPP was allowed to increase, a significant increase in sodium excretion compared with baseline was observed at both doses of L-NMMA (Fig. $1 \mathrm{~A}$ ). In contrast, in snared rats, in whom RPP remained at basal levels, urinary sodium excretion did not increase at 250 $\mu \mathrm{g} \cdot \mathrm{kg}^{-1}$ per min and significantly decreased compared with baseline at the higher dose of L-NMMA. In snared rats, urinary sodium excretion was significantly decreased compared with control rats at both dose levels of L-NMMA. Thus, when the increase in RPP is prevented, intrarenal NO synthase inhibition has a significant antinatriuretic effect. A similar pattern was observed for urine flow rate (Fig. $1 B$ ). In group I rats, L-NMMA infusion resulted in a dose-dependent increase in urine flow rate. In contrast, in group II rats, infusion of $\mathrm{L}$ NMMA induced a marked antidiuretic effect. Fig. $1 C$ shows the effect of intrarenal L-NMMA infusion on urinary protein excretion rate. As can be seen in group I rats, when RPP is allowed to increase, the highest dose of L-NMMA induced a significant increase in protein excretion rate. The proteinuric effect of intrarenal L-NMMA was completely prevented when RPP was maintained at basal levels (group II). Thus, LNMMA-induced proteinuria was dependent on a concomitant increase in RPP.

Study II. Effect of salt-loading on serum $\mathrm{NO}_{2}+\mathrm{NO}_{3}$ levels and urinary $\mathrm{NO}_{2}+\mathrm{NO}_{3}$ excretion rates

Body weight increased significantly over the 2-wk experimental period in both group III (control, baseline vs. final, $280 \pm 3$ vs. $366 \pm 6 \mathrm{~g}, P<0.05$ ) and group IV (salt-loaded, $281 \pm 2$ vs. $355 \pm 2 \mathrm{~g}, P<0.05$ ) rats, however, final body weight was not different between control (group III) and salt-loaded (group IV) rats. Urine sodium excretion increased slightly in group III rats (baseline vs. final, $0.78 \pm 0.27$ vs. $1.90 \pm 0.12 \mathrm{meq} / 24 \mathrm{~h}, P$ $<0.05$ ) consistent with growth. In group IV rats, urine sodium excretion increased dramatically in response to salt loading (baseline vs. final, $0.63 \pm 0.14$ vs. $5.30 \pm 0.66 \mathrm{meq} / 24 \mathrm{~h}, P$ $<0.05, P<0.05$ vs. group III).
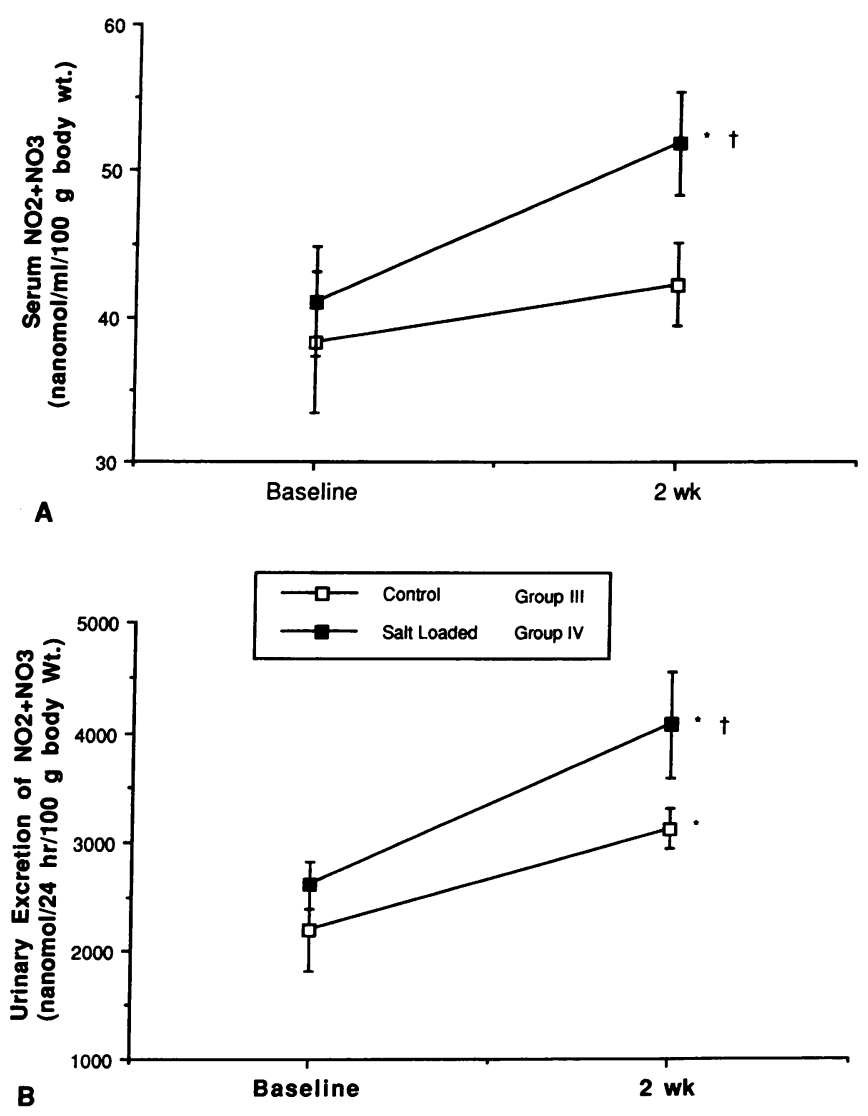

Figure 2. Serum concentrations of $\mathrm{NO} 2+\mathrm{NO} 3(A)$ and urinary $\mathrm{NO} 2$ + NO3 excretion rate $(B)$ in rats of study $\mathrm{II}$, in the baseline and after 2 wk of either normal (group III) or increased (group IV) dietary salt intake. ${ }^{*} P<0.05$ vs. baseline; $\uparrow P<0.05$ group III vs. group IV. 
Serum levels of $\mathrm{NO}_{2}+\mathrm{NO}_{3}$ in group III and group IV rats at baseline and after the 2-wk experimental period are shown in Fig. 2. Baseline values for serum $\mathrm{NO}_{2}+\mathrm{NO}_{3}$ were not different between the two groups (Fig. $2 A$ ). After 2 wk the serum $\mathrm{NO}_{2}$ $+\mathrm{NO}_{3}$ was $41.1 \pm 3.7 \mathrm{nmol} \cdot \mathrm{ml}^{-1}$ per $100 \mathrm{~g}$ body wt in control rats, a value not significantly different from baseline in this group. In contrast, the serum levels of $\mathrm{NO}_{2}+\mathrm{NO}_{3}$ rose significantly in group IV (salt-loaded) rats to $51.9 \pm 3.6 \mathrm{nmol} \cdot \mathrm{ml}^{-1}$ per $100 \mathrm{~g}$ body $w t$. This value was significantly higher than baseline for this group $(P<0.05)$ and, in addition, was significantly higher than the 2 -wk value in group II (control, $P$ $<0.05)$.

Fig. $2 \mathrm{~B}$ demonstrates a significant rise in urinary excretion of $\mathrm{NO}_{2}+\mathrm{NO}_{3}$ in both the control (group III) and salt-loaded (group IV) rats between baseline and 2 wk (Fig. 2 B). However, at the end of the 2-wk experimental period, urinary excretion of $\mathrm{NO}_{2}+\mathrm{NO}_{3}$ was significantly higher in salt-loaded as compared with control rats (group IV vs. group III, 4,078 \pm 478 $\mathrm{nmol} \cdot 24 \mathrm{~h}^{-1}$ per $100 \mathrm{~g}$ body wt vs. $3,123 \pm 182 \mathrm{nmol} \cdot 24 \mathrm{~h}^{-1}$ per $100 \mathrm{gm}$ body wt, $P<0.05$ ). Thus, in these normal rats, salt loading was associated with a significant increase in the serum concentration and urinary excretion of $\mathrm{NO}_{2}+\mathrm{NO}_{3}$. Furthermore, as shown in Fig. 3, when baseline and final values of rats in groups III and IV were considered, there was a highly significant correlation between urinary excretion of $\mathrm{NO}_{2}+\mathrm{NO}_{3}$ and urinary sodium excretion $\left(R^{2}=0.728, P<0.001\right)$.

Group III and group IV rats had similar urinary cGMP excretion rates at baseline (Fig. 4), and cGMP excretion rate increased significantly compared with baseline after $2 \mathrm{wk}$ in both groups of rats. However, as shown in Fig. 4, salt-loaded rats (group IV) demonstrated a greater increase in urinary cGMP excretion rate, reaching a final level that was significantly increased as compared with control rats (group III). Similar to the urinary $\mathrm{NO}_{2}+\mathrm{NO}_{3}$ excretion, urinary cGMP excretion was also significantly correlated with urinary sodium excretion $(P<0.001)$. Finally, we also found a significant and positive correlation between urinary excretion of $\mathrm{NO}_{2}+\mathrm{NO}_{3}$ and cGMP ( $P<0.01$, data not shown), thus confirming an association between these three urinary parameters, and strongly suggesting that salt loading causes increased production of endogenous NO.

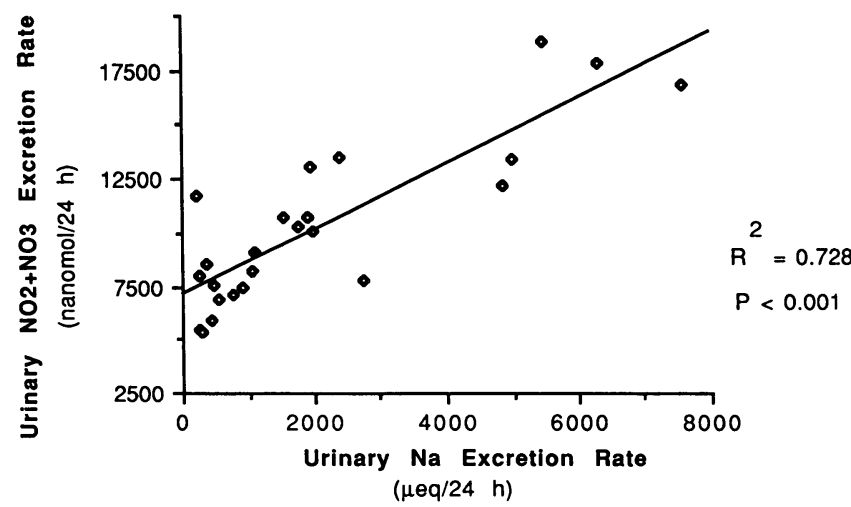

Figure 3. Regression line of urinary $\mathrm{NO}_{2}+\mathrm{NO}_{3}$ excretion rate on urinary sodium excretion rate in rats of study II. Data points are for rats in baseline condition and after 2 wk on either normal (group III) or increased (group IV) salt intake.

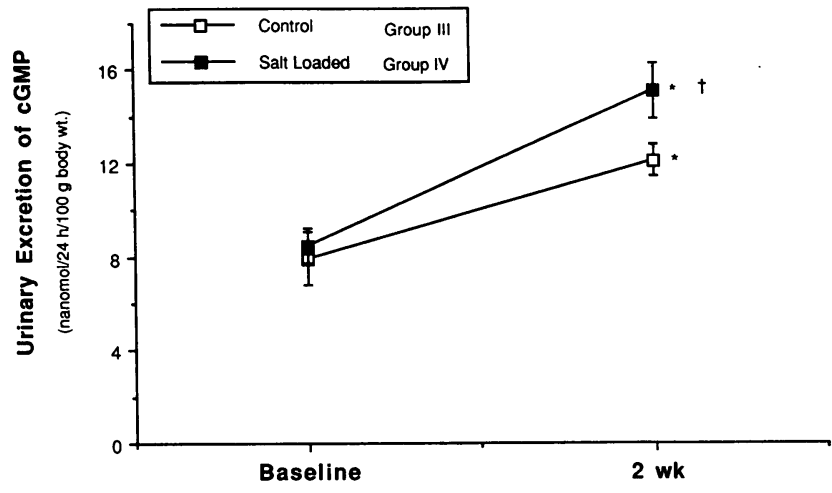

Figure 4. Effect of dietary salt intake on urinary excretion of cGMP in rats of study II. Urinary cGMP excretion is shown in the baseline and after 2 wk on normal (group III) or increased (group IV) salt intake. ${ }^{*} P<0.01$ vs. baseline; $\dagger P<0.05$ group III vs. group IV.

\section{Effect of chronic salt loading on renal hemodynamic responses to NO synthase inhibition}

Values for body weight, left kidney weight, 24-h urine volume, and sodium excretion for rats in group V (control) and group VI ( salt loaded) are shown in Table II. As can be seen, although high dietary salt intake did not significantly effect body weight, salt loading was associated with a significant increase in kidney weight. As expected, urinary sodium excretion rate increased markedly in response to increased salt intake in group VI rats. Urine volume tended to increase as well in group VI compared with group $\mathrm{V}$ rats, but this difference did not achieve statistical significance.

Renal hemodynamic responses to intrarenal NO synthase inhibition are shown in Table III. L-NAME infusion induced a dose-dependent increase in RPP that was similar in magnitude in control and salt-loaded rats. As expected, group V (control) rats demonstrated a dose-dependent decrease in GFR and RPF, whereas RVR significantly increased. These hemodynamic effects were similar to those observed in study I after renal artery infusion of L-NMMA. In group VI rats these changes were directionally similar; however, at the highest dose of L-NAME, GFR fell to a significantly lower level as compared with group $\mathrm{V}$ rats. The fall in RPF and increase in RVR also tended to be of greater magnitude in salt-loaded as compared with control rats, but these differences did not achieve statistical significance. To facilitate comparison of the magnitude of

Table 2. Characteristics of Rats in Group V (Control) and Group VI (Salt loaded) after 2-wk Experimental Period

\begin{tabular}{ccccc}
\hline Group & Body weight & $\begin{array}{c}\text { Left } \\
\text { kidney weight }\end{array}$ & $\begin{array}{c}\text { Urine } \\
\text { volume }\end{array}$ & $\begin{array}{c}\text { Urine sodium } \\
\text { excretion }\end{array}$ \\
\hline & & & $m l / 24 h$ & $m e q / 24 h$ \\
Group V, & & & & \\
control & $391 \pm 4$ & $1.45 \pm .03$ & $16.2 \pm 2.2$ & $2.04 \pm .37$ \\
$P$ value & $\mathrm{NS}$ & $<0.01$ & $\mathrm{NS}$ & $<0.001$ \\
$\begin{array}{c}\text { Group VI, } \\
\text { salt loaded }\end{array}$ & $406 \pm 9$ & $1.65 \pm .05$ & $20.6 \pm 4.6$ & $8.10 \pm 1.10$
\end{tabular}


Table III. Renal hemodynamic parameters of rats in Study II

\begin{tabular}{|c|c|c|c|c|}
\hline Group & RPP & GFR & RPF & RVR \\
\hline & $m m H g$ & & & $m m H g \cdot m^{-1}$ per $m l$ \\
\hline \multicolumn{5}{|l|}{ Group V } \\
\hline Control, baseline & $121 \pm 4$ & $0.93 \pm .05$ & $5.64 \pm .41$ & $11.09 \pm .83$ \\
\hline \multicolumn{5}{|l|}{ L-NAME } \\
\hline $50 \mu \mathrm{g} \cdot \mathrm{kg}^{-1}$ per min & $133 \pm 4^{*}$ & $0.73 \pm 0.4^{*}$ & $3.33 \pm .28^{*}$ & $21.83 \pm 2.47^{*}$ \\
\hline $125 \mu \mathrm{g} / \mathrm{kg} / \mathrm{min}$ & $146 \pm 3^{*}$ & $0.67 \pm .03^{*}$ & $3.00 \pm .23^{*}$ & $26.18 \pm 2.42^{*}$ \\
\hline \multicolumn{5}{|l|}{ Group VI } \\
\hline Salt-loaded, baseline & $124 \pm 4$ & $1.02 \pm .06$ & $5.79 \pm .25$ & $10.85 \pm .57$ \\
\hline \multicolumn{5}{|l|}{ L-NAME } \\
\hline $50 \mu \mathrm{g} / \mathrm{kg} / \mathrm{min}$ & $135 \pm 4^{*}$ & $0.73 \pm .04^{*}$ & $3.31 \pm .17^{*}$ & $20.81 \pm 1.25^{*}$ \\
\hline $125 \mu \mathrm{g} / \mathrm{kg} / \mathrm{min}$ & $145 \pm 4^{*}$ & $0.60 \pm .03^{* \dagger}$ & $2.57 \pm .17^{*}$ & $30.00 \pm 2.69^{*}$ \\
\hline
\end{tabular}

Refer to glossary for definition of terms. All values expressed as mean \pm SEM.

${ }^{*} P<0.05$ vs. baseline; ${ }^{\dagger} P<0.05$ group VI vs. group V same period.

the hemodynamic responses of groups $\mathrm{V}$ and VI to the highest dose of L-NAME, Fig. 5 shows these data expressed as percent change from baseline values. As can be seen in Fig. $5 \mathrm{~A}$, the systemic pressor response was not different in control and saltloaded rats, however, the renal vasoconstrictor response to high-dose L-NAME tended to be greater in group VI (saltloaded) as compared with group V (control) rats $(P=0.06)$. The decrease in GFR and RPF, expressed as percentage change from baseline values, was significantly greater in salt-loaded as compared with control rats (Fig. $5 B$ ). Thus, in rats exposed to

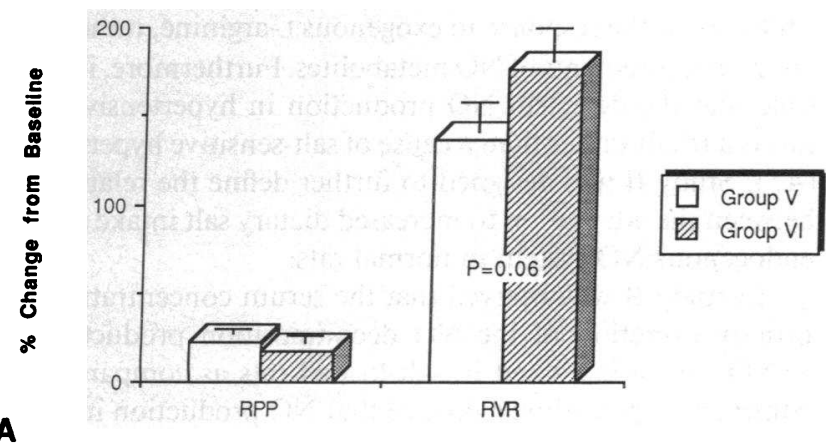

A

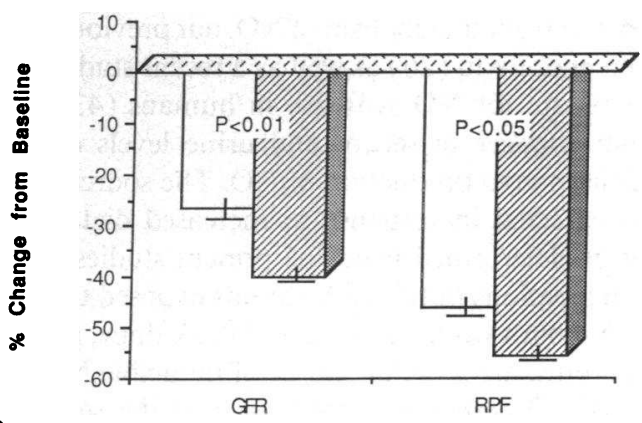

B

Figure 5. Effect of renal arterial infusion of the NO synthase inhibitor, L-NAME ( $125 \mu \mathrm{g} \cdot \mathrm{kg}^{-1}$ per min $)$, on renal hemodynamics in rats of study II, after 2 wk on normal (group V) or increased (group VI) dietary salt intake. $(A)$ Percent change from baseline in RPP and RVR. $(B)$ Percent change from baseline in GFR and RPF. a high dietary salt intake for 2 wk, there was a greater renal hemodynamic response to maximal NO synthase inhibition than was observed in control rats.

\section{Discussion}

Over the last decade it has become increasingly apparent that, in addition to regulation of vascular permeability and control of hemostasis, the vascular endothelium is important in the regulation of vascular tone and regional hemodynamics (30). Investigation in this area has made it clear that control of vascular function by the endothelium is quite complex and involves the balanced synthesis and release of both vasodilator (prostacyclin, EDRF/NO) and vasoconstrictor (endothelin, endothelium-derived contracting factor) substances (31). Modulation of regional hemodynamics by the endothelium has perhaps been best demonstrated by investigations into renal hemodynamics and excretory function.

It has become clear that the vasodilatory action of acetylcholine, when studied in vitro, is due to stimulation and release of the EDRF, NO (1-3). Tolins and coworkers (14) recently demonstrated that the renal hemodynamic effects of acetylcholine in vivo are also mediated by the EDRF, NO. In experimental animals acetylcholine infusion results in decreased systemic blood pressure, a large increase in glomerular capillary plasma flow, but no change in single-nephron GFR, resulting in a fall in filtration fraction $(32,33)$. Acetylcholine infusion has also been reported to have a diuretic and natriuretic effect $(33,34)$. Lahera et al. (35) reported that this acetylcholine-induced diuretic effect was dependent on intact NO synthase activity. Thus, in vivo experimental evidence suggests that stimulation of NO synthesis results not only in vasodilatation, but diuresis and natriuresis as well.

Further evidence supporting a role of NO in modulation of renal function has come from studies using inhibitors of NO synthase in vivo (15-20). These studies suggest that inhibition of endogenous NO synthase results in decreased GFR and renal vasoconstriction with a subsequent increase in filtration fraction. On a microcirculatory level, these changes are associated with a predominant vasoconstrictor effect on the postglomerular circulation, an increase in glomerular capillary 
pressure, and a fall in glomerular ultrafiltration coefficient. However, interpretation of these studies has been complicated due to the simultaneous systemic effects of these NO synthase inhibitors, resulting in increased RPP. It has remained unclear to what degree the effects of inhibition of NO synthase on renal hemodynamics (increased RVR) and excretory function (diuresis and natriuresis) are direct or due to renal responses to increased RPP, such as autoregulation (36) and pressure natriuresis (37), respectively.

In this regard, Radermacher et al. (38) observed that both L-NMMA and nitro-L-arginine increased renal vascular resistance in the isolated perfused kidney of the rat, an experimental model free from systemic hemodynamic influences. Lahera et al. (18) investigated the renal functional response to intravenous infusions of L-NAME in the rat. They reported that during low-dose L-NAME infusion ( $1 \mu \mathrm{g} \cdot \mathrm{kg}^{-1}$ per min i.v.), which did not significantly change systemic arterial pressure, there was a significant decrease in renal sodium and water excretion rate. In contrast, higher doses of L-NAME $\left(50 \mu \mathrm{g} \cdot \mathrm{kg}^{-1}\right.$ per min) induced an increase in systemic blood pressure and were associated with a diuretic and natriuretic effect. Both these studies suggested that NO synthase inhibition had effects on renal hemodynamics and excretory function that were independent of systemic hemodynamic responses.

Study I was designed as an attempt to discern direct from indirect effects of NO synthase inhibition on both renal hemodynamics and excretory function. Our experimental model allowed evaluation of responses of the intact in situ kidney to maximal intrarenal NO synthase inhibition, while preventing any influence of alterations in RPP. We have demonstrated that the renal vasoconstriction and fall in GFR observed during NO synthase inhibition occur, and are perhaps accentuated, when renal perfusion pressure remains constant. This suggests that the renal hemodynamic effects of NO synthase inhibition are due to a direct action on the kidney and not secondary to adaptations such as renal autoregulation. In contrast, it is apparent that the diuresis and natriuresis observed during NO synthase inhibition are indeed secondary to and dependent on the concomitant increase in RPP, and thus represent a pressure natriuresis. These results are in agreement with the work of Johnson and Freeman (21), who previously suggested that systemic inhibition of NO synthase produces a pressure-dependent natriuresis. The results of study I are also consistent with previous reports of a natriuretic effect of agonists of the EDRF, NO, such as acetylcholine $(33,34)$; as well as the work of Alberola et al. (39) in which it was reported that, in the dog, the natriuresis and diuresis induced by extracellular volume expansion with saline was blunted during intrarenal L-NAME infusion. These previous studies suggest that stimulation of NO activity increases renal sodium excretion. Our data suggests that the direct renal effect of inhibition of NO activity is a decrease in sodium excretion. Taken together, these results suggest that activity of the endogenous NO system may play an important role in modulation of renal sodium handling.

In study I we also made the novel observation that acute NO synthase inhibition has a significant proteinuric effect and that this increase in protein excretion is completely prevented by fixing renal perfusion pressure at basal levels. This suggests that the proteinuric effect of NO synthase inhibition is secondary to acute hemodynamic alterations in association with an increase in RPP, most likely increased glomerular capillary pressure and increased filtration fraction (40), hemodynamic changes previously observed during NO synthase inhibition by Zatz and DeNucci (16). Because the increase in proteinuria was prevented in snared rats, we can speculate that the increase in glomerular capillary pressure observed after NO synthase inhibition (16) also depends on an increase in RPP and transmission of this pressure to the glomerular capillary bed. It is interesting that identical glomerular hemodynamic effects and proteinuria have been demonstrated during exogenous angiotensin II infusion in the rat (41). Indeed, previous reports have suggested that part of the renal hemodynamic effect of NO synthase inhibition may be secondary to increased activity of angiotensin II within the glomerular circulation $(15,20)$. It should be emphasized that the mechanism underlying LNMMA-induced proteinuria was not directly addressed in the current study and so the importance of glomerular microcirculatory effects must remain speculative.

The results of study I suggested that the endogenous NO system may play a role in renal sodium handling, with increased NO activity stimulating sodium excretion and decreased NO activity resulting in sodium retention. Furthermore, a recent report by Chen and Sanders (22) suggested that a defect in NO synthesis may underlie the phenomenon of salt-sensitive hypertension in rats. These investigators noted that, in Dahl rats, an increased dietary salt load resulted in increased activity of the NO system in salt-resistant, but not salt-sensitive rats. They hypothesized that the development of salt-sensitive hypertension may be secondary to an inability to enhance NO synthesis in response to increased dietary salt load. However, the conclusions of this study were based predominantly on the hemodynamic response to NO synthase inhibitors or the response to exogenous L-arginine, rather than direct measurements of NO metabolites. Furthermore, it is possible that the defect in NO production in hypertensive Dahl rats is a result rather than a cause of salt-sensitive hypertension (42). Study II was designed to further define the relationship between the adaptation to increased dietary salt intake and the endogenous NO system in normal rats.

In study II we observed that the serum concentration and urinary excretion of the NO decomposition products, $\mathrm{NO}_{2}$ $+\mathrm{NO}_{3}$, were increased in salt-loaded rats as compared with control rats, providing evidence that NO production increases in response to increased dietary salt intake in normal rats. Although the circulating and excreted $\mathrm{NO}_{2}+\mathrm{NO}_{3}$ may not be exclusively derived from metabolism of $\mathrm{NO}$, our previous studies in rats given endotoxin (26) as well as a recent study using ${ }^{15} \mathrm{~N}$-labeled substrate for NO synthase in humans (43) have established that changes in serum and urine levels of $\mathrm{NO}_{2}$ $+\mathrm{NO}_{3}$ do reflect in vivo production of NO. The source of the increased NO detected in response to increased dietary salt intake cannot be determined from the present studies. However, ex vivo incubations of tissues from rats exposed to endotoxin suggest that both vascular tissue and the kidney, particularly the glomerulus, are a major source of inducible NO production $(26,44)$. Whether this holds true in the setting of salt-loading will need to be determined in future studies.

The conclusion that NO production increases in response to increased dietary salt intake is supported by the finding of a significant correlation between urinary sodium excretion, a reflection of intake, and urinary $\mathrm{NO}_{2}+\mathrm{NO}_{3}$ excretion. Similarly, urinary sodium excretion also correlated with urinary cGMP 
excretion, another biological marker of NO activity in vivo $(14,26)$. Moreover, there was a significant correlation between urinary $\mathrm{NO}_{2}+\mathrm{NO}_{3}$ and cGMP excretion rates, providing further evidence that these two markers are related, most likely by reflecting endogenous NO activity. The urinary cGMP excretion rate was significantly increased in salt-loaded as compared with control rats. This latter finding must be interpreted cautiously, however, as an increase in atrial natriuretic peptide levels in response to salt loading could be contributory (44).

The hemodynamic responses of rats in study II to NO synthase inhibition also support our conclusion that increased dietary salt intake increases endogenous NO activity. After 2 wk of exposure to a high dietary salt intake, although baseline renal hemodynamic parameters were similar, intrarenal infusion of L-NAME was associated with a greater decrease in GFR and RPF and a tendency to an enhanced RVR response compared with control rats. This suggests that the basal renal hemodynamic state was characterized by enhanced endogenous NO activity in the salt-loaded group.

In summary, the current study demonstrates that inhibition of NO synthase in vivo results in direct renal hemodynamic and excretory effects, independent of changes in RPP. In particular, NO synthase inhibition is associated with a decrease in urinary sodium excretion when a concomitant increase in RPP is prevented. Furthermore, exposure of normal rats to a high salt diet for 2 wk induces increased NO production as determined by increases in serum concentrations of $\mathrm{NO}_{2}+\mathrm{NO}_{3}$ and increased urinary excretion rate of $\mathrm{NO}_{2}+\mathrm{NO}_{3}$ and cGMP. Chronically salt-loaded rats also demonstrated an enhanced renal hemodynamic response to NO synthase inhibition compared with rats with a normal salt intake. We conclude that the endogenous NO system participates in the physiological renal adaptation to increased dietary salt intake. Clarification of the role of NO in salt-induced hypertension and other pathological conditions associated with abnormal sodium homeostasis awaits future studies.

\section{Acknowledgments}

We thank B. Nyguyen, K. Lewis, and K. Anderson for technical assistance and D. Caruso and M. Helgerson for assistance with manuscript preparation.

This study was supported by funds from the Department of Veterans Affairs.

\section{References}

1. Furchgott, R. F., and V. Zawadski. 1980. The obligatory role of endothelial cells in the relaxation of arterial smooth muscle by acetylcholine. Nature (Lond.). 299:373-376.

2. Ignarro, L. J., G. M. Buga, K. S. Wood, R. E. Byrns, and G. Chandhuri. 1987. Endothelium-derived relaxing factor produced and released from artery and vein is nitric oxide. Proc. Natl. Acad. Sci. USA. 84:9265-9269.

3. Amezcua, J. L., G. J. Dusting, R. M. J. Palmer, and S. Moncada. 1988. Acetylcholine induces vasodilatation in the rabbit isolated heart through release of nitric oxide, the endogenous nitrovasodilator. Br. J. Pharmacol. 95:830-834.

4. Hutchinson, P. J. A., R. M. J. Palmer, and S. Moncada. 1987. Comparative pharmacology of EDRF and nitric oxide on vascular strips. Eur. J. Pharmacol. 141:445-451.

5. Palmer, R. M. J., D. S. Ashton, and S. Moncada. 1988. Vascular endothelial cells synthesize nitric oxide from L-arginine. Nature (Lond.). 333:664-666.

6. Palmer, R. M. J., D. D. Rees, D. S. Ashton, and S. Moncada. 1988. L-argin- ine is the physiologic precursor for the formation of nitric oxide in endothelium dependent relaxation. Biochem. Biophys. Res. Commun. 153:1251-1256.

7. Palmer, R. M. J., and S. Moncada. 1989. A novel citrulline-forming enzyme implicated in the formation of nitric oxide by vascular endothelial cells. Biochem. Biophys. Res. Commun. 158:348-352.

8. Bredt, D. S., and S. H. Snyder. 1990. Isolation of nitric oxide synthetase, a calmodulin-requiring enzyme. Proc. Natl. Acad. Sci. USA. 87:682-685.

9. Rees, D. D., R. M. J. Palmer, H. F. Hodson, and S. Moncada. 1989. A specific inhibitor of nitric oxide formation from L-arginine attenuates endothelium-dependent relaxation. Br. J. Pharmacol. 96:418-424.

10. Dubbin, P. N., M. Zambetis, and G. J. Dusting. 1990. Inhibition of endothelial nitric oxide biosynthesis by $N$-nitro-L-arginine. Clin. Exp. Pharmacol. Physiol. 17:281-286.

11. Moore, P. K., O. A. al-Swayeh, N. W. S. Chong, R. A. Evans, and A. Gibson. 1990. $\mathrm{L}-\mathrm{N}^{\mathrm{G}}$-nitro arginine (L-NOARG), a novel, L-arginine-reversible inhibitor of endothelium-dependent vasodilation in vitro. Br. J. Pharmacol. 99:408-412.

12. Rappaport, R. M., and F. Murad. 1983. Agonist-induced endothelium-dependent relaxation in rat thoracic aorta may be mediated through cGMP. Circ. Res. 52:352-357.

13. Shultz, P. J., A. E. Schorer, and L. Raij. 1990. Effects of endothelium-derived relaxing factor and nitric oxide on rat mesangial cells. Am. J. Physiol. 258:F162-F167.

14. Tolins, J. P., R. M. J. Palmer, S. Moncada, and L. Raij. 1990. Role of endothelium-derived relaxing factor in regulation of renal hemodynamic responses. Am. J. Physiol. 258:H655-H662.

15. Tolins, J. P., and L. Raij. 1991. Effects of amino acid infusion on renal hemodynamics. Role of endothelium-derived relaxing factor. Hypertension (Dallas). 17:1045-1051.

16. Zatz, R., and G. DeNucci. 1991. Effects of acute nitric oxide inhibition on rat glomerular microcirculation. Am. J. Physiol. 261:F360-F363.

17. Baylis, C., P. Harton, and K. Engels. 1990. Endothelial derived relaxing factor controls renal hemodynamics in the normal rat kidney. J. Am. Soc. Nephrol. 1:875-881.

18. Lahera, V., M. G. Salom, F. Miranda-Guardiola, S. Moncada, and J. C. Romero. 1991. Effects of $\mathrm{N}^{\mathrm{G}}$-nitro-L-arginine methyl ester on renal function and blood pressure. Am. J. Physiol. 261:F1033-F1037.

19. King, A. J., J. L. Troy, S. Anderson, J. R. Neuringer, M. Gunning, and B. M. Brenner. 1991. Nitric oxide: a potential mediator of amino acid-induced renal hyperemia and hyperfiltration. J. Am. Soc. Nephrol. 1:1271-1277.

20. DeNicola, L., R. C. Blantz, and F. B. Gabbai. 1992. Nitric oxide and angiotensin II. Glomerular and tubular interaction in the rat. J. Clin. Invest. 89:1248-1256.

21. Johnson, R. A., and R. H. Freeman. 1992. Pressure natriuresis in rats during blockade of the $\mathrm{L}$-arginine/nitric oxide pathway. Hypertension (Dallas). 19:333-338.

22. Chen, P. Y., and P. W. Sanders. 1991. L-Arginine abrogates salt-sensitive hypertension in Dahl/Rapp rats. J. Clin. Invest. 88:1559-1567.

23. Marletta, M. A., P. S. Yoon, R. Lyengar, C. D. Leaf, and J. S. Wishnok. 1988. Macrophage oxidation of $L$-arginine to nitrite and nitrate: nitric oxide is an intermediate. Biochemistry. 27:8706-8711.

24. Beasley, D. J., J. H. Schwartz, and B. M. Brenner. 1991. Interleukin 1 induces prolonged L-arginine-dependent cyclic guanosine monophosphate and nitrite production in rat vascular smooth muscle cells. J. Clin. Invest. 87:602608.

25. Shultz, P. J., M. A. Tayeh, M. A. Marletta, and L. Raij. 1991. Synthesis and action of nitric oxide in rat glomerular mesangial cells. Am. J. Physiol. 261:F600-F606.

26. Shultz, P. J., and L. Raij. 1991. Endogenously synthesized nitric oxide prevents endotoxin-induced glomerular thrombosis. J. Clin. Invest. 90:17181725 .

27. Bartholomew, B. 1984. A rapid method for the assay of nitrate in urine using the nitrate reductase enzyme of Escherichia coli. Ed. Chem. Toxicol. 22:541-543.

28. Granger, D. L., J. B. Hibbs, Jr., J. R. Perfect, and D. T. Durack. 1990. Metabolic fate of L-arginine in relation to microbiostatic capability of murine macrophages. J. Clin. Invest. 85:264-273.

29. Green, L. C., D. A. Wagner, J. Glogowski, P. L. Skipper, J. S. Wishnok, and S. R. Tannenbaum. 1982. Analysis of nitrate, nitrite and ${ }^{15} \mathrm{~N}$ nitrate in biological fluids. Anal. Biochem. 126:131-138.

30. Tolins, J. P., P. J. Shultz, and L. Raij. 1991. Role of endothelium-derived relaxing factor in regulation of vascular tone and remodeling. Update on humoral regulation of vascular tone. Hypertension (Dallas). 17:909-916.

31. Luscher, T. 1990. The endothelium, target and promoter of hypertension? Hypertension (Dallas). 15:482-485.

32. Baylis, C. W., W. M. Dean, B. D. Myers, and B. M. Brenner. 1976. Effects of some vasodilator drugs on transcapillary fluid exchange in renal cortex. $\mathrm{Am}$. J. Physiol. 230:1148-1158. 
33. Baer, P. G., L. G. Navar, and A. C. Guyton. 1970. Renal autoregulation, filtration rate and electrolyte excretion during vasodilatation. Am. J. Physiol. 219:619-625.

34. Early, L. E., and R. M. Friedler. 1965. Studies on the mechanism of natriuresis accompanying increased renal blood flow and its role in the renal response to extracellular volume expansion. J. Clin. Invest. 44:1857-1865.

35. Lahera, V., M. G. Salom, M. J. Fiksen-Olsen, L. Raij, and J. C. Romero. 1990. Effects of NG-monomethyl-L-arginine and L-arginine on acetylcholine renal response. Hypertension (Dallas). 15:659-663.

36. Dewan, S. A. M., and L. G. Navar. 1992. Suppression of blood flow autoregulation plateau during nitric oxide blockade in canine kidney. Am. J. Physiol. 262:F40-F46.

37. Romero, J. C., M. D. Bentley, P. M. Vanhoutte, and F. G. Knox. 1989. Intrarenal mechanisms that regulate sodium excretion in relationship to changes in blood pressure. Mayo Clin. Proc. 64:1406-1424.

38. Radermacher, J., U. Forstermann, and J. C. Frolich. 1990. Endotheliumderived relaxing factor influences renal vascular resistance. Am. J. Physiol. 259:F9-F17.
39. Alberola, A., J. M. Pinilla, T. Quesada, J. C. Romero, M. G. Salom, and F. J. Salazar. 1992. Role of nitric oxide in mediating renal response to volume expansion. Hypertension (Dallas). 19:780-784.

40. Deen, W. M., M. P. Bohrer, and B. M. Brenner. 1979. Macromolecule transport across glomerular capillaries. Kidney Int. 16:353-365.

41. Bohrer, M. P., W. M. Deen, C. R. Robertson, and B. M. Brenner. 1977. Mechanism of angiotensin II-induced proteinuria in the rat. Am. J. Physiol. 233:F13-F21.

42. Luscher, T. F., L. Raij, and P. M. Vanhoutte. 1987. Endothelium-dependent responses in normotensive and hypertensive Dahl rats. Hypertension (Dallas). 9:157-163.

43. Hibbs, J. B., C. Westenfelder, R. Taintor, Z. Vavrin, C. Kablitz, R. L Baranowski, J. H. Ward, R. L. Menlove, M. P. McMurray, J. P. Kushner, and et al. 1992. Evidence for cytokine-inducible nitric oxide synthesis from $L$-arginine in patients receiving interleukin-2 therapy. J. Clin. Invest. 89:867-877.

44. Geryer, R., H. Witzgall, J. Trembley, J. Gutkowska, and P. Hamet. 1985. Rapid increase in plasma and urinary cyclic GMP after bolus injection of atrial natriuretic factor in man. J. Clin. Endocrinol. Metab. 61:1217-1219. 